\title{
Formación pedagógica y análisis de las prácticas ${ }^{1}$
}

Philippe Meirieu ${ }^{2}$

Cafoc: Como diseñador de modelos y practicante en el terreno, usted desarrolla la tesis según la cual existe una brecha irreducible entre decir y hacer, entre la teoría y la práctica. Usted coloca al pedagogo en ese espacio entre lo que él puede organizar mediante diferentes formas de ingeniería y la incertidumbre relacionada con la resistencia, léase a la escapatoria de esas personas a las que se dirige. Ciertas formas de análisis de prácticas desarrolladas hoy dirigidas a los docentes y formadores buscan, más allá de la inteligibilidad de las situaciones educativas, cambiar la acción buscando reducir la distancia entre la teoría profesada por el pedagogo y su teoría practicada. ¿Es compatible su punto de vista con el enfoque que trata de dilucidar y de optimizar las prácticas de los docentes y de los formadores? En otras palabras, según usted, ¿cómo permitir a los pedagogos analizar sus prácticas, si están "condenados a avanzar en el vacío, a asumir irremediablemente el riesgo y la incertidumbre?”

Philippe Meirieu: Para responder a esta pregunta, primero hay que clarificar el estatuto de "teórico" en pedagogía. Lo que traté de mostrar es que en ningún caso es un estatuto "científico" (en cuanto ese discurso procedería por emisión, validación y rectificaciones sucesivas de la hipótesis), sino un discurso "literario" (constituido, con frecuencia de forma heteroclítica, de afirmaciones de carácter profético sobre las finalidades de la educación, de testimonios y de experiencias

\footnotetext{
${ }^{1}$ Este texto corresponde a una entrevista que Philippe Meirieu concedió a formadores del Centro Académico de Formación Continua, CAFOC, de Nantes en 1998. Texto recibido en marzo 16 de 2007 y evaluado en marzo 20 de 2007. Disponible en http://www.meirieu.com/ARTICLES/listes-des-articles.htm en el idioma original (francés). Su traducción al idioma español, con autorización expresa del autor, fue realizada por la traductora oficial Marlen Neira Castro. maneira@cable.net.co.

2 Philippe Meirieu es doctor en letras y ciencias humanas. Profesor de ciencias de la educación en la Universidad de Lumiere-Lyon2. Director del IUFM (Instituto Universitario de Formación de Maestros) de Lyon. E-mail: philippe.meirieu@orange.fr
} 
personales, de proposiciones concretas cuyos efectos se evalúan muy pocas veces, de conminaciones moralizadoras, léase de caricaturas de lo que se trata de rechazar y contra lo cual hay que luchar, el "mal”, estigmatizado con la expresión de "métodos tradicionales"). En ese discurso pedagógico que sin duda encuentra su primera expresión histórica con Pestalozzi, del cual son buenos representantes Montessori, Korckak o Freinet, se halla la forma de expresión de Bloom o de Rogers, a pesar de sus matices de cientificidad. También quedan subyacentes en muchos trabajos de "didáctica". Habiendo anotado eso, el hecho de que ese discurso sea en esencia literario y se presente, con mucha frecuencia, como una forma particular de epopeya (con la denuncia de enemigos, el llamado a agruparse para enfrentarlo, la exaltación del valor de los que quieren verdaderamente "salvar al niño" de todas las trampas que le tiende la sociedad) no lo invalida para nada. El discurso literario es una forma de conocer el mundo muy importante y fecunda, pero a condición de saber leerlo como tal.

En mi opinión, hay que leer los discursos pedagógicos como la expresión de las contradicciones constitutivas de la aventura educativa: contradicción entre el "respeto" que sin cesar afirma sobre el niño y la voluntad de educarlo, de "hacerle el bien", a veces contra su gusto, contradicción entre la necesidad de escucharlo buscando establecer con él una relación lo más auténtica posible, y que se abandone toda veleidad en la enseñanza (es esta forma de "romanticismo pedagógico" que representa bien Rogers) y la preocupación de instrumentarla lo mejor posible y de la manera más rigurosa para él (allí está el proyecto de "tecnología pedagógica” que encarna perfectamente la pedagogía por objetivos y los esfuerzos taxonómicos de Bloom). Contradicción también entre la necesidad imperiosa de considerar al educando como un sujeto en una relación de reciprocidad necesaria a sus aprendizajes y la necesidad de tratarlo simultáneamente como un sometido incapaz (si no iya estaría educado!) de escoger lo que debe aprender y hacer.

A partir del momento en que percibimos el discurso pedagógico como la expresión de esas contradicciones, es posible salir del debate ideológico y de oscilación infernal entre prescripciones que se oponen y tratan de encarnarse de manera totalizante: o bien la no dirección y el dominio de la escucha, o bien la imposición de referenciales no discutibles, o bien la afirmación que el niño ya "es libre" y puede asociarse para decidir de la misma forma que los adultos, o bien la constatación de que no hay ningún modo de ejercer su libertad y debe primero ser "amaestrado". Gracias al rechazo a esas oposiciones sistemáticas, se elaboran, en lo que yo he denominado, según la expresión de Félix Guattari, una “cartografía pragmática” proposiciones de "dispositivos” que tienden a articular exigencias aparentemente contrarias: así lo que llamo el "grupo de aprendizaje" (o sea los dos tomos de Aprender en grupo?) me parece susceptible, de todas formas, de respetar el aporte de cada uno y de permitirle enriquecerse, de conjugar continuidad y ruptura en una tensión constante para reinstalar (y que 
se debe gestionar con los estudiantes cada vez que sea posible) entre la finalización por el proyecto (que corre el riesgo de evacuar los aprendizajes individuales) y la adquisición de nuevas competencias (que corre el riesgo de des-finalizar la actividad individual y colectiva).

En pedagogía nada está escrito en sentido lineal, pero todo se juega en "el entre": entre la autoridad del formador y la autonomía del estudiante; entre el aplazamiento impuesto por obligación al estudiante para que nazca su reflexión y la necesidad de empujarlo a que pase al acto para aprender a hacer algo que no sabe hacer, haciéndolo: entre la racionalidad necesaria de la enseñanza y la circulación inevitable de los afectos; entre tomar en cuenta lo que son las personas y la voluntad de permitirles liberarse; entre una evaluación atributiva que responsabiliza y una evaluación comprensiva que acompaña. En ese "entre cosas", no hay una "teoría científica verdadera” que simplemente se pueda aplicar. Solo hay dispositivos agregados y llenos de contradicciones de los cuales son inevitablemente portadores. En ese "espacio entre cosas", no puede haber certeza absoluta a partir de la cual pudiéramos deducir prescripciones que funcionen "a la fija"; solo hay "mediocridad" y tanteo. Por fortuna eso permite que la educación siga en el campo de la transacción humana.

Dicho lo anterior, su pregunta se plantea ahora en un segundo nivel: cuando hemos identificado un dispositivo que permite esperar vivir de manera positiva contradicciones educativas, ¿se tiene la seguridad absoluta que será eficaz? Mi hipótesis es que no, nunca. Primero porque un dispositivo concebido así no es en nada un "aparato tecnológico" que pueda aplicarse a las personas y que ellas sean de alguna forma el material. Incluso aunque pueda ser concebido a priori, el dispositivo no existe sino en y por la historia de su puesta en marcha, en lo que pone en juego, en lo que reactiva y hace vivir tensiones. Además, nunca tenemos la seguridad de ser eficaces puesto que esa certeza (que es el objeto de una nostalgia permanente del educador y del formador, y sobre la cual pocas veces se reflexiona) haría un impasse por el hecho de que el estudiante es un sujeto que puede decidir crecer y aprender por sí mismo.

El peligro acá sería que, a nombre de tal incertidumbre, cayéramos en el fatalismo: puesto que solo el otro puede decidir aprender, debo dejarlo actuar, y ¡qué lastima si no lo logra! Pero mis poderes sobre la libertad del otro son tan limitados como ilimitados en cuanto a la creación de condiciones que favorezcan la emergencia de esta libertad.

Por tanto, en el campo de la pedagogía diferenciada que yo exploré de forma sistemática, me parece cada vez más que el trabajo del formador no consiste en analizar a priori las “necesidades” de los estudiantes para construir remedios que se adapten perfectamente, sino de conocer y producir remedios múltiples cuyo conocimiento y conservación en lo que llamo la "memoria pedagógica", permite leer y gestionar mejor las situaciones de formación. Los formadores 
que dominan las herramientas de diferenciación son capaces de escuchar "las necesidades" de los alumnos (porque cuentan con una matriz de lectura de ellos) mucho mejor que quienes se obstinan en conocer los alumnos antes de actuar, a riesgo de encerrarlos en una imagen de ellos mismos, o sea de condenarlos a reproducir esta imagen.

CAFOc: En su introducción de La pedagogía entre el decir y el hacer, usted deja de lado el "nosotros" de la escritura universitaria para adoptar el "yo" en unas cuantas páginas. ¿En qué condiciones, según usted, un texto de práctica, la formalización de una experiencia personal en el campo profesional, pueden pretender volverse una oportunidad de formación para otras personas diferentes a quien lo escribe?

PM: No estoy muy seguro de que las condiciones estén del lado de la persona que escribe o de quien cuenta; en ese campo solamente se puede hablar de condiciones de legibilidad y de comunicación. Por el contrario, estoy convencido de que hay condiciones de uso de estos textos en primera persona cuando se quieren volver herramientas de formación para otros. Son las condiciones de lectura, de las cuales dos me parecen esenciales, aunque parezcan contradictorias: el rechazo a interpretar y la voluntad de escuchar lo que se dice allá de la forma que una persona trabaja con las contradicciones fundadoras del acto educativo.

El rechazo a interpretar. Nadie puede pretender tener la verdad del discurso del otro y toda tentativa para reducirlo a categorías psicológicas es ridícula, puesto que sabemos desde Freud que "no es interpretación fuera de la transferencia" y que la persona que pretende decir lo que el otro dice poniéndose en el lugar del otro, habla en realidad de sí mismo. Siempre podré, con un psicoanálisis mínimo, explicar que lo que otra persona dice remite a su relación con la madre, pero esto prueba que esta interpretación no es síntoma de mis problemas con mi madre, y así sucesivamente.

Pero negarse a interpretar, es decir, reducir el discurso o el texto del otro a intenciones singulares supuestas, conscientes o inconscientes, no significa escucharlo ingenuamente en primer grado. Pienso que podemos y debemos buscar en qué sentido ese discurso es portador de la "universalidad educativa", en qué medida habla de cuestiones que son nuestras y que somos capaces de leer acá, puesto que ya las hemos encontrado en nuestra historia y son reconocidas a través de otros textos, literarios por ejemplo.

CAFoc: Precisamente, en sus escritos, hace referencia a numerosos textos literarios y obras cinematográficas como materiales para pensar la relación pedagógica. ¿En qué sentido pueden ser ellos vectores facilitadores de análisis de prácticas 
profesionales? En qué condiciones, según usted, esos elementos se vuelven activadores para cuestionar la actuación profesional, para fundar o volver a fundar la forma singular de vivir el oficio?

PM: Los textos literarios no deben constituir un nuevo "remedio milagroso" en materia de formación de formadores. No reivindico para nada que ellos ocupen todo el espacio. Deseo simplemente interrogar el supuesto implícito, hoy tan dominante, según el cual solo lo "científico" es formador. En ningún caso, evidentemente, deseo alejar la psicología cognitiva o social, la sociología, la epistemología o la filosofía de la formación de materias y de formadores. Pero lo que caracteriza la educación como actividad específica de los hombres es que se trata de una acción singular irreductible a categorías previas, que pone en juego en cada momento el discernimiento y la decisión del educador así como la movilización de herramientas o conceptos prestados a las disciplinas auxiliares. Formarse como profesional de la educación no es solo dominar las herramientas o las matrices de análisis, sino también actuar con inteligencia en las situaciones particulares a las que se verá confrontado, aunque no hayan sido estudiadas.

En ese sentido a veces acepto estar de acuerdo con la opinión de los que afirman que "la pedagogía es un arte", pero me niego por completo a que caigamos (lo que se hace con mucha frecuencia) en la afirmación que "la pedagogía es un don”. La práctica de un arte se aprende de manera diferente de la práctica de una técnica puramente reproductiva e instrumental (aunque podamos preguntarnos si esas técnicas existen de verdad). La práctica de un arte es diferente a la aplicación del saber hacer o incluso de "saberes de acciones" muy elaborados; ella supone una "sensibilidad" particular que, en materia de educación, remite a la comprensión de las apuestas propiamente humanas de la empresa. Ahora bien, el acceso a esta conciencia puede facilitarse gracias a la lectura de textos y al estudio de obras que, precisamente, llevan la singularidad al nivel de la ejemplaridad. La literatura cumple acá la función de "bucle": por su efecto de "engrosamiento" y la eficacia del uso específico de la lengua, que es el suyo, permite ver y comprender lo que está en juego cuando una persona trata de educar a otra. Obviamente nunca encontraremos situaciones idénticas, pero las experiencias de situaciones particulares, probablemente nos harán más lúcidos en otras situaciones.

Entiéndame bien, no quiero decir que la frecuentación de obras de arte dé acceso automáticamente a la humanidad; el nazismo tristemente nos mostró lo contrario. Sin embargo, lo sabemos bien, frecuentar la ciencia y dominar la tecnología tampoco. Ambas formas de cultura (no tan opuestas, en realidad) son medios para sostener una determinación primera que es siempre, de hecho, de orden ético. 
Cafoc: Numerosos enfoques de trabajos de educación y de formación se basan actualmente, en Francia, en un paradigma del comportamiento y se traducen en la formalización de repertorios o de referenciales de competencias. Si ese movimiento contribuye a la transformación estructural de esos trabajos en profesiones, según usted, permite aprehenderlos completamente?

PM: No es seguro que podamos dejar de lado el conductismo en la formación ¿Quizá constituya incluso un tipo de higiene mental necesaria que nos permite luchar contra algunas trampas de nos tienen nuestras complicidades afectivas y sociales? La insistencia en el anuncio de objetivos y la evaluación de comportamientos observables siguen siendo buenas murallas que nos protegen contra algunos desvíos que siempre están presentes, amenazantes, desde que se establece una relación pedagógica. Así mismo, es bastante sano crear referenciales de trabajo y esto es incluso una de las condiciones para que su trasmisión no caiga en lo inefable. Pero una cosa es crear esos referenciales y usarlos como herramientas reguladoras en la formación y otra cosa es creer que un trabajo se reduce a la suma de competencias y de las capacidades necesarias para ejecutarlo. Un trabajo es siempre otra cosa: una manera de aprehender el mundo, de organizar cierto universo simbólico, de funcionar con ciertos ritos, de adherirse a cierto número de valores más o menos explícitos, de situarse en una deontología, etc. Si los formadores ignoran esta dimensión del trabajo, corren el riesgo mayor de sufrir las críticas de los que estigmatizan su ineficacia. La reducción tecnicista es uno de los peores servicios que se puedan prestar a los estudiantes y, al final, es uno de los mayores riesgos que corren los formadores y la formación. Me parece que debemos trabajar hoy en una nueva dirección, lo cual nos permitirá formar no solamente habilidades reproducibles o incluso competencias transferibles, sino también una verdadera "cultura de los saberes de la formación". Esta cultura es precisamente la manera en que un oficio, en una sociedad dada, comprende el mundo y responde, en su campo propio, a los interrogantes antropológicos esenciales. 